\title{
A Study on Application of Neural Networks in Assessment of Computer Network Security
}

\author{
Jifeng Shen ${ }^{1,}$, Jun $\mathrm{Xu}^{1, \mathrm{~b}}$, Kang $\mathrm{Li}^{1, \mathrm{c}}$ and Ke Yang ${ }^{1, \mathrm{~d}}$ \\ ${ }^{1}$ Information Management Center, Training Department of Armored Force Institute, Bengbu 233050, \\ China \\ a32487012@qq.com, bujunfff @163.com, '601035514@qq.com, d191892938@qq.com
}

\begin{abstract}
Keywords: Computer network security assessment; Neural Network; Application; Study.
Abstract. With the progress of information era and popularity of computer networks, network security has become a focus of attention.As an important part of study on computer network security, network security assessment is of great value and significance for maintenance of network information security, system security and implementation of reasonable precaution measures. As such, this paper presents a new evaluation method,namely the neural network evaluation, which is an abstract mathematical model good for realization of final objectives through network learning by certain rules. Therefore, this paper mainly gives an analysis of basic content of neural network and the necessity of its application in evaluation of computer network security. Meanwhile, this paper summarizes the specific application of neural network in evaluation of network security.
\end{abstract}

\section{Introduction}

Neural networks is the connector of a large number of neuron nodes and when its weight distribution converges to a stable sate, all neuron nodes composing the neural network would be in the best condition. In such case, evaluation of computer network security can be conducted. Before the evaluation, a comprehensive analysis of the factors that may affect security of computer network security shall be carried out and those factors shall be quantified as certain characteristic indexes and included in a index set to be used in modeling of neural network.With the use of existing system and evaluation results, the neural network can provide direct assessment of new similar systems according to certain characteristics. Therefore,this paper is of vital value and meaning for study of the application of neural network in computer network security assessment.

\section{Overview of Neural Networks}

(I) Definition of neural networks

Neural network is a complex integrated network system, and network development is motivated by simulating people's perception of the outside world information by the cranial nerve system. As a result, the neural network can be regarded as the connector of a large number of neuron nodes.Neural network is not a regular network system in general sense, but an abstract mathematical model, and the final shape of the model is dependent on stability of the weight distribution of the neural network. That is to say, when the weight distribution of neural network converges to a stable state, all neuron nodes composing the neural network would be in the best condition. At this moment, learning and modification of the network can be ceased.With regard to problem solving in neural network, different kinds of problems usually correspond to different neural networks and different input and output modes can be obtained for the purpose of judging the rationality of the problem [1].

(II) Classification of neural network models

Classification of neural network models involves in four parts: neurons, types of neural network, transfer function of neural network, and learning and training of neural network. From the perspective of analysis of neurons,classification of neural network models includes biological neurons and artificial neurons. Difference and correlation of the two types of neurons is as shown in Table 1[2]. 
Table 1 Comparison of Biological Neurons and Artificial Neurons

\begin{tabular}{|c|c|c|c|}
\hline Types of Neurons & Composition & Characteristics & Difference \\
\hline Biological neurons & body, & kinc & $\begin{array}{l}\text { Correlation } \\
\text { Biological neurons }\end{array}$ \\
\hline & dendrites, & $\begin{array}{l}\text { excitatory state and } \\
\text { inhibitory state }\end{array}$ & $\begin{array}{l}\text { are the foundation of } \\
\text { artificial neurons and }\end{array}$ \\
\hline Artificial neurons & $\begin{array}{l}\text { A function model: } \\
\text { input, output, the } \\
\text { network weight and } \\
\text { threshold, summation } \\
\text { unit, transfer function }\end{array}$ & $\begin{array}{l}\text { Multiple input and } \\
\text { output, non-linear node } \\
\text { simulated nerve cell }\end{array}$ & $\begin{array}{lr}\text { artificial neurons } & \text { are } \\
\text { obtain } & \text { by } \\
\text { simplification } & \text { and } \\
\text { simulation } & \text { of } \\
\text { biological neurons } & \end{array}$ \\
\hline
\end{tabular}

Neural networks are in a great variety due to diversity of system layers of the biological neural networks. Such as, perceptron,BP neural network, feedback neural network and self-organizing map network are the typical neural network models. In addition, based on neuron interconnection structure, the neural networks can be classified into forward network without feedback, interconnection network, forward Network with mutual combination among layers and forward network with feedback between the input and output layers. Table 2 gives the neural network features of different neuron interconnection structures[3].

Table 2 Neural Network Features of Different Neuron Interconnection Structures

\begin{tabular}{|c|c|c|}
\hline $\begin{array}{l}\text { Type of Network } \\
\text { Interconnection } \\
\text { Structures }\end{array}$ & $\begin{array}{c}\text { Graphical } \\
\text { Representation }\end{array}$ & Features \\
\hline Forward network & 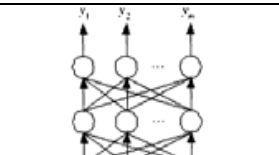 & $\begin{array}{l}\text { Layered distribution of all the neurons, } \\
\text { namely the input layer, hidden layer and output } \\
\text { layer from the top to the bottom }\end{array}$ \\
\hline $\begin{array}{l}\text { Interconnection } \\
\text { network }\end{array}$ & & $\begin{array}{l}\text { All the neurons linking with each other in a } \\
\text { ball shape }\end{array}$ \\
\hline $\begin{array}{l}\text { Forward Network with } \\
\text { mutual combination } \\
\text { between layers }\end{array}$ & $t$ & $\begin{array}{l}\text { Neurons at different layers being connected } \\
\text { to a certain extent }\end{array}$ \\
\hline $\begin{array}{l}\text { Forward Network with } \\
\text { Feedback }\end{array}$ & & $\begin{array}{l}\text { Feedback between the input layer and the } \\
\text { output layer }\end{array}$ \\
\hline
\end{tabular}

Comparison of types and basic forms of neural network transfer functions is as shown in Table 3. 
Table 3 Comparison of Types and Basic Forms of Neural Network Transfer Functions

\begin{tabular}{|c|c|c|}
\hline $\begin{array}{c}\text { Types of Transfer } \\
\text { Functions }\end{array}$ & Function Expression & Function Graph \\
\hline Threshold function & $\begin{array}{c}\text { When } \mathrm{x}\rangle \\
\mathrm{x}<0, \mathrm{f}(\mathrm{x})=0\end{array}$ & $\mathrm{f}(\mathrm{x})=1$, when \\
\hline Linear function & $\mathrm{f})=\mathrm{kx}$ & $\mathrm{f}(\mathrm{x})=1 /(1+\mathrm{e}-\mathrm{x})$ \\
\hline Sigmoid-type function & $2)$ & \\
\hline Gauss-type function & & \\
\hline
\end{tabular}

According to the learning modes of neural network, the neural network can be divided into learning with supervisor, learning without supervisor and reinforcement learning, among which, learning with supervisor, learning without supervisor can be also called as supervised and unsupervised learning. Supervised learning refers to network training implemented on the basis of certain amount of training samples.During the training process, certain principles and training methods are used for guidance along with verification realized by input and output, the learning is completed upon realization of the objectives.Unsupervised learning is a kind of self-organized learning mode, which is conducted without samples for training but by responding to input signal in accordance with certain rules and constant modification of the threshold and weight until the value obtained are in stable distribution[4].

\section{II.Computer Network Security Assessment}

(I) Content and features of computer network security assessment

In essence, computer network security assessment refers to the process of analyzing capability of the network system resisting hazards such as hacker attack, user data leakage, and various virus and pointing out the hidden troubles in the computer network system so as to provide along corresponding precaution measures. Computer network security assessment is mainly characterized with complexity, diversity and particularity etc.

(II) Necessity of computer network security assessment

With the development of computer network technology, application of computer network has become more and more popular, computer network users users can access abundant information resources stored in the global network system without leaving home. In addition, economic, cultural, military and social events are growing increasingly dependent on computer network. Hence, study on computer network security becomes a hot issue worthy of attention. For study on relevant problems involving in computer network security, network security assessment is an integral element and directly related to selection of subsequent operation and precaution measures involving in computer network security. Given all that, it is necessary for study on computer security assessment in this paper.

\section{Application of Neural Networks in Computer Network Security Assessment}

(I) Fields of application of neural networks

Neural networks are applied in the following fields: first pattern recognition, such as voice recognition doll, image recognition for face detection; second, consumer electronic and electrical products, such as neural network control in air conditioning equipment and fuzzy neural network control in full-automatic washing machines; third, robots, for example, intelligent fault detection; finally, medicine, Medical image processing technology etc.[.6] 
(II) Necessity of application of neural networks in computer network security assessment

For general approaches in computer network security assessment, such as inductive reasoning, deductive reasoning judgment, in the process of assessment, objects are mainly based on non-linear relation, but with those methods, it is hard to reflect the relationship between the index attributes. Consequently, it is quite common that assessment results obtained under different ways contradict with each other. However, with the use of neural networks, direct assessment of similar new systems can be conducted based on existing systems and assessment results. It can not only enhance efficiency of assessment but also reduce influence of various kinds of uncertain factors. Therefore, it is quite necessary to apply neural networks in computer network security assessment.

(III) Specific application of neural networks in computer network security assessment

A summary of the specific application of neural networks in computer network security assessment is given in Table 4.

Table 4 Procedures of Application of Neural Networks in Computer Network Security Assessment

Content of Application $\quad$ Application Advantages $\quad$ Problems needing Attention

Computer network Centralized assessment Accuracy of assessment security assessment models indexes, highly systematic and index set and breadth of content based on neural networks accurate

Neural networks learning Fixed learning period, high to be improved learning quality and high number of nodes and assessment objectives establishment of index factor correlation

Optimization of Neural Simple optimization method Timely observation of networks and obvious results weight distribution of neuron nodes

Output assessment of Highly accurate and Form of the interaction neural network comprehensive assessment with fewer fuzzy factors between the input and output layer to be well handled

\section{Conclusion}

To sum up, by analysis of relevant content of neural networks, this paper gives a detailed description of the features and types of neural networks and explains the characteristics and importance of computer network security assessment through analysis of the basic conditions of computer network security assessment. And then, by analyzing application of neural networks in computer network security assessment, this paper expounds the necessity and feasibility of such application. Finally, this paper summarizes the basic procedures, advantages and problems needing attention in application of neural networks in computer network security assessment.

\section{References}

[1]Kalyani S, Swarup K S. STUDY OF NEURAL NETWORK MODELS FOR SECURITY ASSESSMENT IN POWER SYSTEMS[J]. International Journal of Research \& Reviews in Applied Sciences, 2009, 1(2).

[2]Kung, Yang C H, Kung W S, et al. A Study on Image Quality Assessment using Neural Networks and Structure Similarty[J]. Journal of Computers, 2011, 6(10):2221-2228.

[3]Kheradpisheh, Z, Talebi, A, Rafati, L, et al. Groundwater quality assessment using artificial neural network: a case study of Bahabad plain, Yazd, Iran.[J]. Desert, 2015.

[4]Blinowska K J, Brzezicka A. Application of directed transfer function and network formalism for the assessment of functional connectivity in working memory task.[J]. Philosophical Transactions of the Royal Society A Mathematical Physical \& Engineering Sciences, 2013, 371(371):618-618. 
[5]Zhong-Wu L I, Chen L Q, University B. Application of neural network in evaluation of computer network security[J]. Open Electrical \& Electronic Engineering Journal, 2014, 8(1):766-771.

[6]Khalyasmaa A I, Dmitriev S A, Kokin S E, et al. Fuzzy neural networks' application for substation integral state assessment[J]. Energy Production \& Management in Century, 2014:599-605. 